\title{
POR UMA PEDAGOGIA LITERÁRIA DO “COMO SE": EM TORNO DE UMA EXPERIÊNCIA PEDAGÓGICA NA GRADUAÇÃO EM LETRAS DA UFMG
}

Nabil Araújo*

RESUMO: Este artigo relata a experiência pedagógica em Teoria da Literatura conduzida pelo autor na graduação em Letras da Universidade Federal de Minas Gerais (UFMG) à época de seu doutorado em Estudos Literários na mesma instituição. Essa experiência, aqui convertida, ela própria, em objeto de reflexão teórica, suscita uma compreensão renovada do ato crítico em jogo na leitura/avaliação de textos literários, bem como a proposta de uma pedagogia literária aqui chamada - sob a inspiração do livro clássico de Hans Vaihinger, Die Philosophie des Als $\mathrm{Ob}$ [A filosofia do como se] - de "Pedagogia do Como Se".

Palavras-chave: Teoria da Literatura. Crítica Literária. Ensino de Literatura. Pedagogia do "Como Se".

* Doutor em Estudos Literários pela Universidade Federal de Minas Gerais (UFMG) e Professor da Universidade Federal de Minas Gerais (UFMG). Email:nabil.araujo@gmail.com 


\title{
FOR A LITERARY PEDAGOGY OF “AS IF": AROUND A PEDAGOGICAL EXPERIENCE IN THE UNDERGRADUATE COURSE OF LETTERS AT UFMG
}

\begin{abstract}
This article reports the pedagogical experience in Theory of Literature conducted by the author in the undergraduate course of Letters at Universidade Federal de Minas Gerais (UFMG) during his doctorate in Literary Studies at the same institution. This experience, here converted into an object of theoretical reflection, entails a renewed comprehension of the critical act at stake in the reading/evaluation of literary texts, as well as the proposition of a literary pedagogy called here - under the inspiration of the Hans Vaihinger's classical book, Die Philosophie des Als $\mathrm{O} b$ [The philosophy of as if] - "Pedagogy of As If".
\end{abstract}

Keywords: Theory of Literature. Literary Criticism. Teaching of Literature. Pedagogy of "As If".

\section{ENSINO DE LITERATURA E CRÍTICA LITERÁRIA}

O que é que de fato se ensina sob a rubrica escolar/ acadêmica de "ensino de literatura"? Não, bem entendido, a literatura propriamente dita, e sim a crítica literária, a basear-se no célebre postulado de Northrop Frye, em sua clássica Anatomy of criticism [Anatomia da crítica], publicada em 1957, de que "em nenhum ponto existe qualquer aprendizado direto da própria literatura", de que "se aprende sobre ela de um certo modo, mas o que se aprende, transitivamente, é a crítica da literatura", de que "a crítica da literatura é tudo o que pode ser diretamente ensinado" (FRYE, 1971, p. 11). ${ }^{1}$ Mais de uma década antes, no prefácio à publicação de sua tese de livre-docência, de 1945, Antonio Candido já havia subsumido o ensino de literatura na crítica literária, nos seguintes termos:

No cerne do estudo e do ensino da literatura está o problema crítico. De um modo geral, o problema literário apresenta três aspectos: a criação artística, o público e, entre ambos, uma série de intermediários cuja função é esclarecer e sistematizar. É o papel que compete às diferentes modalidades de crítica, desde a história literária até a resenha de jornal, e delas depende em boa parte a formação e o desenvolvimento da consciência literária. O ensino da literatura pode e deve ser considerado um aspecto da crítica (CANDIDO, 1988, p. 9; grifo meu).

Em havendo, pois, algo como uma demanda pedagógica pela crítica literária - ou, mais especificamente, pela competência crítica por ela implicada -, é justo indagar se a forma tradicionalmente assumida pelo "ensino de literatura" em nossas escolas realmente 
corresponde a tal demanda. Atenhamo-nos, quanto a isso, àquela, dentre as "diferentes modalidades de crítica" evocadas por Antonio Candido, que se consolidou como modelo hegemônico de estudo literário em nosso Ensino Médio: a "história literária" - mais especificamente, a História da Literatura Brasileira, focada num conjunto de autores e obras canônicos distribuídos por estilos de época que se sucedem, cronológica e progressivamente, dos séculos XVI/XVII à contemporaneidade. Pensemos, então, na forma como a demanda pedagógica por competência crítica se encontra expressa nos Parâmetros Curriculares Nacionais para o Ensino Médio (PCNEM) voltados para a área de "Linguagens, códigos e suas tecnologias: Língua portuguesa", no momento em que se postula como competência de "investigação e compreensão" a ser desenvolvida pelo aluno: "Emitir juízos críticos sobre manifestações culturais" (BRASIL, 2002, p. 65). Esclarece-se, aí, que: "A formulação de opiniões sustentadas por argumentos é condição para construir um posicionamento sobre manifestações culturais que se sucedem no tempo e no espaço"; e que: "Não basta considerar algo como belo ou não; é preciso saber de que premissas se parte para valorizar determinados procedimentos de ordem estética, sem perder de vista que tais valores são variáveis no tempo e no espaço" (Ibid., p. 65).

Ora, parece evidente que uma história literária arquitetada e difundida de modo a antes ocultar do que explicitar a "premissa" em que se baseia para "valorizar determinados procedimentos de ordem estética" - no caso, como pertencentes ao honorável conjunto da Literatura Brasileira - não pode proporcionar ao aluno a possibilidade de "construir", por meio da "formulação de opiniões sustentadas por argumentos", um "posicionamento sobre manifestações culturais que se sucedem no tempo e no espaço", à guisa de um verdadeiro "juízo crítico" sobre os autores e as obras com que trava contato, já que o próprio modo pelo qual os autores e as obras em questão são então apresentados e estudados pressupõe que o juízo crítico acerca dos mesmos já tenha sido formulado, e de maneira peremptória. Tal como no campo religioso, a canonização (de autores e obras), também aí, implica uma instância ativa (o sujeito da canonização), circunscrita a um restritíssimo círculo de autoridade, e uma instância passiva (os beneficiários do cânone), extensiva a todos aqueles a quem cabe submeter-se às decisões da autoridade canonizadora, reproduzindo acriticamente seus posicionamentos. As atividades pedagógicas de um ensino literário assim concebido convertem-se, de acordo com os PCNEM, numa "camisa de força incompreensível": (a) "A 
história literária costuma ser o foco da compreensão do texto; uma história que nem sempre corresponde ao texto que lhe serve de exemplo" (BRASIL, 2000, p. 16); (b) "O conceito de texto literário é discutível. Machado de Assis é literatura, Paulo Coelho não. Por quê? As explicações não fazem sentido para o aluno" (Ibid., p. 16). E ainda:

Outra situação de sala de aula pode ser mencionada. Solicitamos que alunos
separassem de um bloco de textos, que iam desde poemas de Pessoa e Drummond
até contas de telefone e cartas de banco, textos literários e não literários, de acordo
como são definidos. Um dos grupos não fez qualquer separação. Questionados,
os alunos responderam: "Todos são não literários, porque servem apenas para
fazer exercícios na escola". E Drummond? Responderam: "Drummond é literato,
porque vocês afirmam que é, eu não concordo. Acho ele um chato. Por que Zé
Ramalho não é literatura? Ambos são poetas, não é verdade?" Quando deixamos
o aluno falar a surpresa é grande, as respostas, quase sempre surpreendentes.
Assim pode ser caracterizado, em geral, o ensino de Língua Portuguesa no Ensino
Médio: aula de expressão em que os alunos não podem se expressar (Ibid., p. 16).

Em se permitindo, afinal, ao aluno simplesmente "se expressar", como aí se sugere, quais seriam as consequências disso para o ensino de literatura, ou melhor, para o desenvolvimento da competência crítica no Ensino Médio? Nada boas, de acordo com as Orientações Curriculares para o Ensino Médio (OCEM), documento no qual (em vista, justamente, da passagem acima citada) os PCNEM são acusados de uma "ênfase radical no interlocutor, chegando ao extremo de erigir as opiniões do aluno como critério de juízo de uma obra literária, deixando, assim, a questão do 'ser ou não ser literário' a cargo do leitor” (BRASIL, 2006, p. 58). Na prática, essa postura seria encarnada por um "professor que lança mão de todo e qualquer texto, de Fernando Pessoa a raps, passando pelos textos típicos da cultura de massa" e que "se considera libertário (por desconstruir o cânone) e democrático (por deselitizar o produto cultural)", mas cuja postura, pretensamente "libertária ou democrática", não passaria, no fim das contas, de "permissiva" (Ibid., p. 56). ${ }^{2}$ Daí, a pergunta: "Qual seria então o lugar do rap, da literatura de cordel, das letras de músicas e de tantos outros tipos de produção, em prosa ou verso, no ensino da literatura?" (Ibid., p. 56); à qual se responde que "muitos deles têm importância das mais acentuadas [...] por serem significativos dentro de determinado contexto, mas isso ainda é insuficiente [...] se não revelarem qualidade estética" (Ibid., p. 56-57); que, em suma: "Qualquer texto escrito, seja ele popular ou erudito, seja expressão de grupos majoritários ou de minorias, contenha denúncias ou reafirme o status quo, deve passar pelo mesmo crivo que se utiliza para os escritos canônicos" (Ibid., p. 57). 
A se tomar, então, a "qualidade estética" como o "crivo que se utiliza para os escritos canônicos", dir-se-ia explicitada, enfim, a "premissa" normalmente empregada para "valorizar determinados procedimentos de ordem estética" em detrimento de outros. Assim sendo, poder-se-ia postular: são canônicos os textos literários que possuem qualidade estética. Esta, por sua vez, se associaria àquilo que, num texto literário, estimula a "fruição estética", a saber: "a sensação de estranhamento que a elaboração peculiar do texto literário, pelo uso incomum de linguagem, consegue produzir no leitor" (Ibid., p. 55). Mas avultam, com isso, então, dois problemas. O primeiro é o de determinar por que razão, afinal, o "estranhamento" (gerado pelo "uso incomum de linguagem"), e não algum outro efeito ou característica, é que deve ser tomado como indicador maior da qualidade estética de um texto. A associação entre "estranhamento" e "literariedade" remonta, como se sabe, aos chamados formalistas russos, e como se lê, a certa altura, nas próprias OCEM:

Houve diversas tentativas de estabelecimento das marcas da literariedade de um texto, principalmente pelos formalistas e depois pelos estruturalistas, mas essas não lograram muito sucesso, dada a diversidade de discursos envolvidos no texto literário. Mais recentemente, deslocou-se o foco do texto para o leitor (visto esse como coprodutor do texto) e para a intertextualidade, colocando-se em questão a autonomia e a especificidade da literatura (Ibid., p. 55-56).

O segundo problema é que, mesmo se se aceitasse o "uso-incomum-de-linguagem-a-gerar-estranhamento" como indicador maior de uma pretensa qualidade estético-literária, o reconhecimento dessa característica nos textos existentes estaria longe de ser inequívoco, havendo sempre, como admitem as OCEM, "uma boa margem de dúvida nos julgamentos" (Ibid., p. 57). Em se tomando, por exemplo, a tradição romanesca no Brasil, simplesmente não se pode comprovar haver um mesmo "uso de linguagem", dito "incomum", compartilhado por figuras tão díspares quanto Macedo, Alencar, Machado, Azevedo, Lima Barreto, Mário de Andrade, Graciliano Ramos, Clarice Lispector e Guimarães Rosa, a um só tempo inverificável em outros romancistas reputados "sem qualidade estética" - a menos, é claro, que se esteja apoiado, nesse caso, na boa e velha autoridade canônica, invertendo-se, aliás, o postulado acima esboçado, numa evidente petição de princípio: possuem qualidade estética os textos literários que são canônicos. Eis-nos de volta à estaca zero.

Para além da oposição estéril entre permissividade multiculturalista e autoritarismo canônico, ambos inaptos a desenvolver a competência crítica dos alunos, permanece, portanto, 
o grande desafio a ser enfrentado por uma pedagogia literária na contemporaneidade: "Ou bem nos empenhamos na construção de competências que permitam ao aluno emitir juízo crítico sobre os bens culturais ou continuamos a nos conformar com o dogmatismo, cristalizado no magister dixit' (BRASIL, 2002, p. 51). O que se segue enuncia-se como uma resposta possível a tal desafio.

\section{DAS TEORIAS CRÍTICAS E SUA (SOBRE)VIVÊNCIA EM SALA DE AULA}

Ao longo de 2009, segundo ano de meu doutorado em Estudos Literários na Faculdade de Letras da UFMG, ocupei, na mesma instituição, a vaga de professor substituto de Teoria da Literatura para a qual havia sido aprovado em concurso realizado no fim do ano anterior. No primeiro semestre, ministrei a disciplina "Teoria da Literatura I" (cujo programa contempla, além de uma introdução à problemática geral da Teoria da Literatura, os fundamentos do estudo e da análise da narrativa) para três turmas de calouros, cada qual com pouco mais de 40 alunos inscritos.

Logo no início do curso solicitei aos alunos que respondessem um questionário que continha, dentre outras, as seguintes questões: (a) "O que é literatura?"; (b) "O que é boa literatura, literatura de qualidade?"; (c) "O que quer dizer saber ler bem uma obra literária? Em que consiste a boa leitura, a leitura correta de uma obra literária?". A variedade das respostas a cada uma das questões foi considerável, e isso apesar de aquele grupo de alunos ter sido submetido, ao longo de sua formação escolar prévia, ao mesmo tipo de educação literária, descontadas algumas variações e especificidades (uma parte do referido questionário destinava-se, justamente, a traçar um perfil geral dessa base escolar prévia dos alunos, bem como a identificar suas impressões a respeito do modo como o ensino da literatura havia sido conduzido em suas respectivas escolas). ${ }^{3}$

Identificando certos padrões em meio à variedade de respostas, pudemos, juntos, separá-las em quatro grandes grupos, cada um deles correspondente a uma determinada concepção de literatura (e, associadamente, de crítica literária): ${ }^{4}(1)$ as respostas que apontavam para uma suposta capacidade/função da obra literária de "refletir", "espelhar", "representar", etc., "a realidade", "o mundo", "a sociedade", "as relações pessoais", etc., foram agrupadas sob a denominação: literatura como REPRESENTAÇÃO; (2) as respostas que apontavam para uma suposta capacidade/função da obra literária de "entreter", "ensinar", "fazer refletir", etc., foram agrupadas sob 
a denominação: literatura como EFEITO; (3) as respostas que apontavam para uma suposta capacidade/função da obra literária de "manifestar", "expressar", etc., "as ideias", "os sentimentos", "a alma", etc., de um autor ou da coletividade a que ele estaria integrado, foram agrupadas sob a denominação: literatura como EXPRESSÃO; (4) as respostas que, de um modo geral, apontavam para uma suposta natureza da obra literária como "obra de arte", "construção", "forma", "estrutura", etc., foram agrupadas sob a denominação: literatura como LINGUAGEM.

Em vista dessa triagem inicial, não podia deixar de me lembrar da célebre classificação das teorias críticas segundo sua "orientação" elaborada mais de meio século atrás por M. H. Abrams na introdução a seu The mirror and the lamp [O espelho e a lâmpada] (1953), clássico da historiografia da crítica. Observando o quanto a diversidade de teorias críticas dificulta o trabalho do historiador, Abrams propõe, então, "um quadro de referência simples o bastante para ser facilmente manejável, mas flexível o bastante para que, sem violência indevida a qualquer conjunto de afirmações sobre a arte, possa traduzir tantos conjuntos quanto possível num único plano de discurso" (ABRAMS, 1971, p. 5), quadro esse elaborado a partir dos quatro elementos que, "na situação total de uma obra de arte", explica Abrams (Ibid., p. 6), "são discriminados e salientados, por um ou outro sinônimo, em quase todas as teorias que visam ser abrangentes", a saber: a própria (a) "obra" [work], isto é, "o produto artístico em si mesmo", além do (b) "artista" [artist] que a produziu, do (c) "universo" [universe] de que ela trata e do (d) "público" [audience] ao qual ela se dirige. "Embora qualquer teoria razoavelmente adequada tenha alguma consideração por todos os quatro elementos, quase todas as teorias", acrescenta Abrams, "exibem uma perceptível orientação para um deles apenas"; e ainda: "um crítico tende a derivar de um desses termos suas principais categorias para definir, classificar e analisar uma obra de arte, bem como os principais critérios por meio dos quais ele julga seu valor" (Ibid., p. 6).

Às teorias que se orientam para o "universo" de que trata a obra, então concebida como imitação de aspectos desse "universo", Abrams (Ibid., p. 8-14) chama de "miméticas" [mimetic theories]; àquelas orientadas para o "público" a que se dirige a obra, então concebida como um meio ou instrumento para se alcançar um fim, isto é, para se obter uma resposta precisa do público, ele chama de "pragmáticas" [pragmatic theories] (Ibid., p. 14-21); àquelas orientadas para o "artista" 
que produziu a obra, então concebida como um interior (do artista) tornado exterior, ele as chama "expressivas" [expressive theories] (Ibid., p. 21-26); àquelas, finalmente, orientadas para a "obra" em si mesma, então concebida como uma entidade autossuficiente, isolada de todos os pontos de referência externos, ele chama de "objetivas" [objective theories] (Ibid., p. 26-28). "De acordo com o nosso esquema de análise, então, tem havido quatro principais orientações, cada uma das quais tendo parecido a várias mentes perspicazes adequada para uma crítica satisfatória da arte em geral", conclui Abrams, acrescentando que, de seus primórdios ao início do século XIX, a "progressão histórica" [historic progression] da crítica ocidental se dera, em termos gerais: "da teoria mimética de Platão e (de um modo qualificado) Aristóteles, através da teoria pragmática - perdurando, desde a fusão da retórica com a poética na era helenística e românica, quase todo o século XVIII -, até a teoria expressiva da crítica romântica inglesa (e, um pouco antes, alemã)" (Ibid., p. 28).

No contexto acadêmico em que Abrams então escrevia o de princípios da década de 1950 nos EUA -, um novo momento hegemônico, o da "teoria objetiva", parecia já ter se consolidado nessa alegada progressão da crítica: "Pelo menos na América certa forma do ponto de vista objetivo já foi demasiado longe a ponto de deslocar seus rivais como o modo reinante de crítica literária” (Ibid., p. 28). Mais de três décadas depois, Abrams (1989) estará em condições de traçar de modo mais claro e completo o panorama da hegemonia objetivista na crítica literária do século XX, evocando movimentoschave como o formalismo russo e o estruturalismo francês, para enfocar, em seguida, o New Criticism, estendendo, além do mais, sua abordagem, aos principais desenvolvimentos da crítica acadêmica norte-americana nas décadas de 1960 a 1980: "Poststructuralism", "Reader-response Criticism", "Deconstruction". Seria plenamente factível, acrescente-se, mantendo-se o esquema analítico de Abrams, estender até os nossos dias o panorama da "progressão histórica" do mainstream da crítica ocidental, de modo a abarcar os movimentos teóricos que avultaram e ganharam força internacionalmente desde o fim da década de 1980, como os "Estudos pós-coloniais" [Postcolonial Studies] e os "Estudos de gênero" [Gender Studies].

A discriminação que fizéramos em sala de aula das teorias críticas em função de sua definição da literatura como "representação", "efeito", "expressão" ou "linguagem" lembrava, pois, em larga medida, a antiga classificação de Abrams das teorias críticas em função de sua orientação para o "universo", o "público", 
o "artista" ou a "obra". Era de se esperar que - e os alunos pareciam mesmo ansiar por isso -, feita a triagem inicial, eu procurasse esclarecer, então, quais dessas teorias estariam, na verdade, mortas - não passando, agora, de, digamos, "curiosidades de opinião há muito extintas" -, ou, ao menos, deveriam estar mortas, em vista do que se sabe ser (ou do que se deveria saber ser) o modo correto de abordagem crítica da obra literária. ${ }^{5}$

Tal gesto pressuporia, é certo, determinada imagem da história da crítica, daquilo que se diria encontrar-se, então, definitivamente superado em vista de um presente epistemológico que, se eventualmente não vem a ser concebido como ponto de chegada necessário (telos) de um determinado percurso passível de reconstituição pelo historiador da crítica, no mínimo erige-se como ponto de vista privilegiado a partir do qual se julgar o que é correto ou desejável, afinal, e o que não é, em termos de crítica literária. Partindo, ao contrário, da constatação de que "doutrinas críticas" diversas encontravam-se vivas nas respostas de meus alunos, quando deveriam estar mortas (deveriam?); colocando em suspenso o tipo de parti pris que me levaria, muito naturalmente, ao paradoxo de declará-las mortas apesar de vivas; admitindo, em suma, que, de alguma forma e por alguma razãa, elas (sobre)viviam, ali, entre aqueles alunos (apenas entre eles?), não era o caso, pois, de me indagar sobre a forma e a razão de tal (sobre)vivência?

\section{DIANTE DA LEI: UMA TEMPORADA COM KAFKA}

Dando prosseguimento ao curso, entreguei aos alunos uma folha com "Diante da lei" [Vor dem Geset:], de Franz Kafka, na tradução de Modesto Carone, ${ }^{6}$ texto desconhecido de praticamente todos eles. Depois de ler em voz alta a narrativa, pedi-lhes, sem maiores explicações, que registrassem, numa folha à parte, as observações críticas sobre a mesma que então julassem pertinentes. ${ }^{7}$

Nos textos produzidos - chamemo-los protocolos -, as diversas teorias críticas anteriormente elencadas ressurgiram, dessa vez, em ato, isto é, encarnadas num comentário crítico efetivo de uma narrativa determinada. Poder-se-ia dizer que o que caracterizava, em conjunto, a manifestação de tais teorias nos protocolos era justamente seu caráter naturalizado, isto é, a aparente naturalidade com que o princípio da literatura-como-representação, ou o da literatura-como-efeito, ou o da literatura-como-expressão, ou o da literatura-como-linguagem, vinha a determinar, então, em cada caso - quase sempre tacitamente e, 
por isso mesmo, sem o aporte de nenhuma justificativa -, a estipulação da natureza e do valor da narrativa lida. Atendo-se, pois, aí, ao modo de enunciação dessas teorias, dir-se-ia terem sido internalizadas pelos autores dos protocolos como que por efeito de doutrinação. ${ }^{8}$

Escritos os protocolos, a indagação acerca de qual teoria crítica, enfim, seria a correta e quais não seriam voltava ainda com mais força e urgência, agora inevitavelmente entrelaçada à indagação acerca de qual a leitura correta, afinal, dentre as várias apresentadas, da pequena narrativa de Kafka. Os alunos portavam-se, então, um tanto à maneira do "homem do campo" de "Diante da lei", como que aguardando do professor-porteiro a palavra, o gesto, a indicação, enfim, que lhes possibilitaria o tão aguardado acesso à "lei" da narrativa e da leitura literária! Em vez disso, seguiu-se uma dinâmica pedagógica que seria bem definida, a princípio, como um procedimento de levantamento e verificação de hipóteses.

Posto que a tendência prevalente nos protocolos em geral havia sido a de tomar a narrativa kafkiana como representando, ainda que indiretamente - por "metáfora", "símbolos", etc. -, um determinado estado de coisas de natureza fosse social, fosse política, fosse propriamente jurídica, fosse, ainda, religiosa, e isso com vistas a algum tipo de ensinamento de fundo moral ou moralizante a ser supostamente assimilado pelo leitor, a primeira hipótese que se impunha era a de que a teoria crítica correta fosse justamente a que toma a literatura como REPRESENTAÇÃO de uma dada realidade ou estado de coisas, mas também, e sem prejuízo da primeira função, como EFEITO a ser gerado no leitor por uma tal representação como o faz, aliás, a tradicional teoria dos gêneros literários veiculada por nossos programas escolares, fundamentalmente voltada (ao menos no que tange aos gêneros dramático e épico) para as regras ou os parâmetros de representação (mas também de efeito) a que um texto deveria conformar-se a fim de se enquadrar neste ou naquele gênero particular. Ocupando-nos, assim, numa sequência de aulas expositivas, de um conjunto selecionado de textos teóricos atinentes à referida teoria dos gêneros (capítulos de manuais de teoria literária, verbetes de dicionários especializados, panoramas históricocríticos sobre a "questão dos gêneros"), solicitei, em seguida, que os alunos elaborassem uma nova leitura crítica de "Diante da lei", agora à luz dos textos teóricos estudados, produzindo, com isso, um novo protocolo, teoricamente orientado. A título de subsídio para essa tarefa, selecionei e disponibilizei, além do mais, peças de autorias diversas da fortuna crítica kafkiana que pareciam, em maior 
ou menor grau, coadunar-se com o tipo de abordagem teórica a ser então trabalhado, e das quais os alunos poderiam então se servir livremente na elaboração de seus novos protocolos.

$\mathrm{O}$ arcabouço teórico em questão revelou-se inegavelmente produtivo no trato da narrativa pelos alunos, permitindo-lhes desenvolver seus comentários críticos em rumos diversos, e, mesmo, inesperados, nem sempre convergentes uns com os outros, mas sempre coerentes com o princípio geral da literatura-comorepresentação-e-efeito da teoria dos gêneros. Assim, se houve consenso geral em relação ao caráter "alegórico" do texto de Kafka, bem como uma tendência hegemônica a tomá-lo como pertencente ao gênero "parábola", houve discordâncias acerca da natureza dessa alegada parábola kafkiana, de suas raízes judaicas ou não, de seu teor religioso ou não - para muitos, o teor seria, antes, eminentemente político-social, ou filosófico, quiçá profético, num sentido muito mais histórico do que religioso. Houve discordância também acerca de sua significação global - isto é, da moral por ela supostamente encerrada - e de detalhe - isto é, do significado e da função a serem atribuídos a cada um dos personagens e dos elementos nela presentes. Houve, ainda, certa incongruência na especificação do modus operandi parabólico em Kafka, e, consequentemente, do valor a ser atribuído ao texto como realização de um gênero literário: para alguns, "Diante da lei" encarnaria, em vista das regras do gênero, uma parábola perfeita, e haveria nisso, por si só, um grande valor, enquanto que, para outros, o texto claramente subverteria esta ou aquela regra do gênero, afastando-se, com isso, em certos pontos, da parábola por excelência, a bíblica, e nisso é que residiria seu valor maior.

Essas e outras nuances ficam patentes na leitura dos textos constantes da primeira parte de Diante da lei: uma experiência em Teoria da Literatura - caderno da coleção "Viva Voz" (FALE/ UFMG) reunindo protocolos por mim selecionados e organizados, publicado em 2010 -, intitulada "Gêneros literários: mímesis e normatividade" (ARAÚJO, 2010, p. 19-40). Numa visão de conjunto, o que mais chama a atenção quanto às discrepâncias internas aí avultadas é justamente essa internalidade das mesmas: em face do referido grupo de protocolos, tem-se a nítida impressão de que foram escritos por pessoas sob um mesmo regime de leitura crítica, isto é, que compartilham uma mesma concepção do fazer crítico, um mesmo referencial teórico, um mesmo instrumental analítico, ao modo de pesquisadores regidos por um mesmo "paradigma", trabalhando colaborativamente num regime de 
"ciência normal", para empregar dois termos tornados célebres por Thomas Kuhn (cf. KUHN, 1996). Dir-se-ia, assim, que as eventuais incongruências entre os autores dos protocolos acerca desta ou daquela questão de enquadramento, de atribuição de significado ou de valoração da narrativa lida só se tornam aí perceptíveis sobre esse fundo de comprometimento coletivo com um mesmo e único "paradigma" crítico, cuja vigência não se veria, portanto, em nenhum momento, concretamente ameaçada por tais incongruências, perfeitamente toleráveis em seu interior. A oportunidade para uma eventual "mudança paradigmática" não poderia advir, nesse caso, ao que tudo indica, senão de fora para dentro.

Eis que é levantada, então, em nosso curso, uma segunda hipótese a ser verificada. Quando da elaboração em sala de aula daquele primeiro protocolo de leitura por mim solicitado, por assim dizer, à queima-roupa, alunos alegaram uma provável influência da vida do autor na conformação da narrativa lida; alguns disseram que lhes parecia impossível realizar a contento a tarefa na mais completa ausência de informações de ordem histórico-biográfica sobre o autor da narrativa, como era o caso. E se a teoria crítica correta fosse mesmo, antes, aquela que toma a literatura como EXPRESSÃO das "experiências", dos "sentimentos", das "ideias" do escritor?

Lançando mão do mesmo procedimento adotado quando da primeira verificação de hipótese, ocupamo-nos, num primeiro momento, em aulas expositivas, de um conjunto selecionado de textos teóricos centrados na questão da autoria na literatura (e contrários ao enquadramento crítico por gêneros literários), fosse de nomes centrais do cânone crítico oitocentista como Sainte-Beuve e Taine - cuja influência se faz presente, ainda hoje, quando quer que se aborde o fenômeno literário pelo viés "vida-e-obra" -, fosse de ícones da teoria crítica do século XX como Benedetto Croce e Georges Poulet, passando por Marcel Proust.. Para além desse corpus teórico, devidamente escrutinado e comentado em sala de aula, novos textos do próprio Kafka foram introduzidos na discussão, como a célebre Carta ao pai [Brief an der Vater] e uma narrativa tão aparentemente autobiográfica como "O veredicto" [Das Urteil] (sempre na tradução de Carone), a essa altura automaticamente associados, por grande parte dos alunos, também a outros célebres enredos kafkianos frequentemente evocados ao longo do curso, como os de $O$ processo [Der Prozess] e $A$ metamorfose [Die Verwandlung]. Tendo disponibilizado aos alunos, a título de subsídio, trechos diversos de biografias de Kafka, bem como peças da fortuna crítica 
do autor ilustrativas do novo tipo de abordagem a ser trabalhado, solicitei-lhes, então, uma nova leitura crítica de "Diante da lei", um novo protocolo teoricamente orientado.

Em face da amostra desses novos protocolos reunida na segunda parte de Diante da lei: uma experiência em Teoria da Literatura (ARAÚJO, 2010, p. 41-69), tem-se a nítida percepção de uma "mudança paradigmática" em relação ao conjunto de textos da primeira parte: em vez da concepção da literatura-como-representaçãoe-efeito, da teoria dos gêneros, impõe-se, agora, a concepção geral da literatura-como-expressão-de-uma-dimensão-autoral. Diferentemente do primeiro conjunto, no qual, sob um regime de leitura crítica homogêneo, as eventuais discordâncias e incongruências incidem no nível estrito do enquadramento, da atribuição de significado e da valoração da narrativa lida, nesse novo conjunto, a própria unicidade, a própria homogeneidade do regime de leitura crítica em questão parecem ameaçadas pela divisão aí observada no modo de se conceber e de se tratar a "dimensão autoral" de que a literatura seria a expressão: teria ela um caráter pré-textual, isto é, de causa externa, anterior e determinante do texto literário (biografia/psicologia do autor, fatores sociais, históricos, econômicos, etc.) à qual seria preciso remontar a fim de se explicar o texto ou um caráter subtextual, isto é, de uma espécie de causalidade profunda subjacente à superfície textual à qual se acederia tão somente por um trabalho de interpretação?

Essa dicotomia já se encarnava, na verdade, nas duas perspectivas em que se encontrava dividido o conjunto de textos teóricos discutidos por ocasião de nossa segunda verificação de hipóteses: aquela de uma leitura crítica biografista e historicista, direcionada à busca das causas externas determinantes da obra literária, então representada por Sainte-Beuve e por Taine; e aquela de uma leitura crítica de feição hermenêutica, direcionada ao "eu profundo" plasmado na obra e irredutível às referidas "causas externas", então representada por Benedetto Croce, por Georges Poulet, e pelo Marcel Proust do incisivo manifesto Contre Sainte-Beuve. $\mathrm{Na}$ ausência de quaisquer indicações de minha parte categoricamente pró ou contra qualquer uma das duas perspectivas, os alunos se vendo livres para articular seus protocolos no sentido que julgassem mais apropriado, alguns deles simplesmente ignoraram uma das perspectivas e retomaram a narrativa de Kafka exclusivamente à luz da outra; outros procuraram, de alguma forma, e com maior ou menor sucesso, conciliar em seu protocolo ambas as perspectivas, apontando para uma possível complementaridade 
entre elas; outros, ainda, explicitando a franca oposição entre as duas, adotaram um determinado posicionamento em detrimento do outro, apoiando-se, quanto a isso, no argumento deste ou daquele teórico de um dos dois lados.

Curiosamente, contudo, a imagem de "Diante da lei" que emergiu dessa etapa parecia mais homogênea do que a emersa na etapa anterior. A narrativa avultava agora, basicamente, como uma reação de Kafka à realidade extremamente opressora a que estivera submetido em sua própria vida - sobretudo em vista da relação com seu pai, Hermann Kafka -, com os personagens e outros elementos da narrativa encarados fosse numa chave mais estritamente biográfica - "homem do campo" = Franz; "porteiro" = Hermann; "lei" = realização pessoal, etc. - , fosse numa chave mais amplamente histórico-social, como elementos da atmosfera política, jurídica, religiosa e ideológica na qual esteve imerso Kafka durante sua atribulada existência.

Se a dicotomia teórica no âmbito do regime de leitura crítica pautado pela concepção da literatura-como-expressão-de-uma-dimensãoautoral pareceria desautorizar, a princípio, que se postulasse aí em funcionamento algo como um único e mesmo paradigma crítico, a divergência entre as referidas perspectivas teóricas tendia, contudo, a soar como menor do que a afinidade entre elas quando comparadas, ambas, em conjunto, à perspectiva teórica homogeneamente vigente no regime de leitura crítica instaurado na etapa anterior. Isso levou a que se encarasse, em última instância, a tal dicotomia, nos termos de uma diferença teórica interna a uma macroperspectiva expressiva, por assim dizer, em crítica literária (daí, inclusive, o título da segunda parte de nossa coletânea de protocolos: "Autor/autoria: pré-texto x subtexto"). Essa percepção se vê definitivamente reforçada, aliás, à luz da condenação em bloco de toda e qualquer remissão à dimensão autoral, pré ou subtextual, em crítica literária promovida pelo conjunto de textos teóricos estudados na terceira e última etapa de nossa experiência com os protocolos, por ocasião da verificação de uma terceira e última hipótese de trabalho: a de que a teoria crítica correta seria, na verdade, a que considera a literatura em si mesma, estritamente como ser de LINGUAGEM.

Em aulas expositivas, como de costume, ocupamo-nos primeiramente de três textos teóricos atinentes ao que se convencionou chamar, à guisa de um tópico em teoria da literatura, de "a morte do autor" - um de Maurice Blanchot, um de Roland Barthes e um de Michel Foucault. Na sequência, detivemo-nos em textos de teóricos 
americanos da close reading ["leitura cerrada"] em crítica literária. Textos adicionais do próprio Kafka foram introduzidos na discussão - três outras breves narrativas de Um médico rural [Ein Landarat], livro em que se encontra "Diante da lei" -, e uma nova seleção de textos críticos sobre o autor (de autoria de Jorge Luis Borges, Milan Kundera, Wolfgang Kayser) foi disponibilizada, a título de subsídio, aos alunos, a quem solicitei, então, uma nova leitura crítica de "Diante da lei", um novo protocolo teoricamente orientado.

A amostra dessa derradeira leva de protocolos reunida na terceira e última parte de Diante da lei: uma experiência em Teoria da Literatura - intitulada "A obra-em-si: organicidade e autorreferencialidade" (ARAÚJO, 2010, p. 71-99) - revela uma nova reorientação de regime de leitura crítica, agora francamente pautado por uma concepção da literatura-como-instauração-de-uma-realidade-pelalinguagem, sustentada pelos alunos com base seja na teoria francesa da morte do autor e do nascimento da "écriture", seja na teoria americana da obra como "estrutura" a ser cerradamente escrutinada, seja num cruzamento ou numa combinação de ambos os "formalismos", o francês e o americano. O homem Franz Kafka e as vicissitudes de sua biografia ou psicologia profunda agora cedem lugar ao "kafkiano", concebido como universo em que vigora "o absurdo", "o grotesco", "a desesperança", mas não a título daquela realidade exterior e anterior ao texto que caberia à obra literária - de acordo com a concepção da literatura-como-representação - imitar ou espelhar a posteriori, e sim, ao contrário, de uma realidade que emerge do e com o próprio discurso literário em questão; o "kafkiano", em suma, concebido como um universo não representado, mas instaurado pela linguagem, pela escrita de Kafka, e do qual "Diante da lei" seria um perfeito exemplar.

\section{ATO CRÍTICO: DUPLA DECISÃO NO INDECIDÍVEL}

Finda essa última etapa, impunha-se a sensação de se ter percorrido, ao longo do curso, aquela "progressão histórica" da teoria crítica ocidental outrora delineada por M. H. Abrams: da teoria "mimético-pragmática" de filiação platônico-aristotélica às teorias ditas "objetivas" do século XX, passando-se pelas teorias "expressivas" de filiação romântica. Parece mesmo haver, num caso como esse, uma tendência automática a se confundir progressãa (temporal) com progresso (epistemológico), e isso, provavelmente, por força da arraigada concepção acumulativista de conhecimento científico em função da qual, como observa Kuhn (1996, p. 171): 
"Estamos todos profundamente acostumados a ver a ciência como um empreendimento que se aproxima, cada vez mais perto, de algum objetivo estabelecido de antemão pela natureza". Mas que evidências haveria, afinal, no caso de nossa experiência com os protocolos, de que a última etapa da mesma, a "objetivista", corresponderia, de fato ou de direito, a um ponto de chegada natural da demanda pela teoria crítica correta e pela leitura crítica correta da narrativa de Kafka?

Não há dúvida de que se podem encontrar nos textos teóricos estudados na referida etapa fortes argumentos em favor da concepção da literatura-como-linguagem em detrimento das demais, bem como da necessidade de se pautar a leitura crítica pela obra em si, isolada de quaisquer fatores externos. Mas o que ficou comprovado ao longo do percurso foi que argumentos não menos fortes podem ser encontrados nos conjuntos de textos estudados em cada uma das duas outras etapas, argumentos a favor, respectivamente, da concepção da literatura-como-representaçãoe-efeito e da concepção, ou melhor, das concepções da literaturacomo-expressão-de-uma-dimensão-autoral.

Podemos, no fim das contas, identificarmo-nos, cada um de nós, com este ou aquele argumento deste ou daquele teórico, mas isso, por si só, não nos autoriza a alçá-lo, a tal argumento, ao estatuto de meta-argumento universal, isto é, de parâmetro metateórico e meta-histórico à luz do qual se decretar a validade ou a invalidade das teorias críticas em geral. Sobretudo quando se está, quanto a isso, numa posição institucionalmente privilegiada como a do professor em face de seus alunos, a adoção tácita de um argumento como meta-argumento a ser intersubjetivamente compartilhado não poderia desembocar senão numa prática crítica naturalizada (doutrinária, portanto).

Talvez pudéssemos pôr um termo na querela das teorias críticas em sala de aula indagando-nos por aquela que teria proporcionado, enfim, uma maior "iluminação" da narrativa de Kafka - e aí, uma vez mais se confundindo progressão (temporal) com progresso (epistemológico), poder-se-ia querer postular a superioridade da perspectiva "objetivista" sobre as demais por encontrar-se ela no fim de um processo no qual ininterruptamente buscou-se iluminar por completo um texto que, desde o início, soava tão surpreendentemente obscuro em sua aparente clareza. Mas se, de fato, cada mudança de regime de leitura crítica experimentada ao longo do curso acarretara a emergência de uma nova imagem de "Diante da lei", na ausência de um critério metaimagético neutro, 
por assim dizer, que possibilitasse decretar qual dessas imagens seria, por princípio, a mais "verdadeira", ou, mesmo, a mais "rica", a mais "interessante", a mais "iluminadora", enfim, impunha-se reconhecer que o simples surgimento de uma nova imagem não implicava por si só a superação das demais, mas apenas a existência de mais uma possivel leitura crítica correta de "Diante da lei".

As diferentes leituras críticas implicadas pelas diferentes imagens de "Diante da lei" afiguravam-se, pois, todas elas, possivelmente corretas, mas não, bem entendido, compossivelmente corretas, já que mutuamente excludentes entre si. Uma escolha era assim requerida: uma decisão entre as diversas possibilidades de leitura crítica correta de "Diante da lei". Ora, uma leitura crítica não pode, a rigor, afigurar-se "correta" senão à luz de um dado princípio de correção, daquele princípio epistemológico-axiológico que a tornaria, enfim, factível como correta, havendo, entretanto, nesse caso, tantos possíveis princípios de correção quantos eram os posicionamentos teóricos então em disputa - e também isso comporia, portanto, a matéria da referida decisão, a qual se mostrava, nesses termos, a um só tempo necessária e impossível.

Assim sendo, a decisão em jogo no ato crítico diz respeito não apenas ao juízo de gosto em face da obra lida, mas também, e de um só golpe, ao princípio teórico à luz do qual o referido juízo de gosto se faz possível - princípio teórico esse que, por isso mesmo, não se encontra, em nenhuma medida, dado apriori e pronto para ser aplicado, mas que deve ser obtido no próprio ato crítico, o que se quer, então, chamar de ato crítico confundindo-se, na verdade, em larga medida, com essa obtenção de princípio. Essa obtenção - enfatize-se - traduzse numa determinada escolha, numa determinada decisão, aquela entre possibilidades diversas e divergentes de princípios teóricos para o juízo de gosto inerente à prática crítica, uma decisão em ato, pois, para a qual, bem entendido, não há nem pode haver nenhuma garantia externa ao próprio ato crítico como ato de escolha, dupla.

Desse modo, a conclusão segundo a qual "[a] lição de toda crítica é a de que não temos nada com que contar ao fazer nossas escolhas a não ser nós mesmos" (RICHARDS, 1956, p. 328-329) apontaria para uma operação que se dá não num vácuo absoluto de regras ou princípios, e, sim, ao contrário, num horizonte de possibilidades múltiplas e divergentes de regras ou principios, em vista das quais se requer, então, uma decisão, sem garantias. A angústia inerente à escolha crítica não seria, pois, a da carência total de princípios, mas, antes, a da abundância de potenciais princípios. 
Diferentemente de alguém que tivesse seu acesso à lei dificultado pela presença ameaçadora de um porteiro à frente da única porta disponível para tanto, o grande desafio do leitor crítico de "Diante da lei" não era, pois, qualquer tipo de obstáculo físico à "lei" da narrativa, e, sim, antes, a multiplicidade de portas de acesso à mesma, todas elas possíveis, mas não compossíveis, cabendo a ele, portanto, não apenas a decisão entre as diversas portas possíveis, mas o tornar a porta escolhida, e por força mesma dessa decisão, a única porta correta de acesso à "lei" da narrativa, a única das entradas da qual se poderia dizer ter sempre estado destinada a ele, leitor crítico, e a mais ninguém.

Um último protocolo de leitura a ser escrito pelos alunos não poderia ser, assim, senão a performance desse acesso único a uma entrada única, em meio a outras (incom)possíveis entradas. Desnaturalizadas as concepções inadvertidamente em jogo numa primeira abordagem, teoricamente desarmada, da narrativa de Kafka e revelado o solo de indecidibilidade subjacente ao consenso teórico em vigor no âmbito de regimes de leitura crítica funcionando em sua "normalidade", as teorias críticas já não podiam ser nem simplesmente ignoradas nem simplesmente aplicadas ao texto literário: sua manifestação em ato, por assim dizer, implicava, agora, é certo, um trabalho consciente por parte do leitor crítico, a saber, não um mero exercício de relativismo judicativo no qual o leitor se servisse livremente, e sem maiores consequências, deste ou daquele instrumental de leitura de acordo com sua conveniência, mas a performance responsável de uma determinada decisão crítica bem como de sua justificativa. Um comando conveniente para esse último protocolo de leitura bem que poderia ser: esforce-se por convencerme de que eu deveria enxergar e valorar "Diante da lei" da maneira como você aqui e agora o faz, e não de outra maneira.

\section{A LIC̣ÃO SEM LIC̣ÃO: POR UMA PEDAGOGIA LITERÁRIA DO “COMO SE”}

Se a grande lição a ser daí extraída é mesmo a de que o verdadeiro ato crítico traduz-se numa dupla decisão a partir de um horizonte de indecidibilidade epistemológico-axiológica, numa dupla decisão, portanto, a um só tempo necessária e impossível, associa-se a ela uma lição talvez ainda maior, e de suma importância do ponto de vista pedagógico, que se faz derivar da constatação de que aquela primeira lição não poderá nunca ser transmitida ao modo de uma lição (isto é, de um conteúdo constativo-propositivo ensinável como tal); de que não há teoria possível daquela lição (a qual permanece 
irredutível, pois, a qualquer teorema); de que ou ela é vivenciada como tal, no bojo de uma experiência como aquela de meus alunos com seus protocolos, "uma experiência em Teoria da Literatura", ou ela acarreta, em si mesma, como pretensa lição, nada menos do que a morte daquilo mesmo que ela gostaria de ensinar.

Mas aquela experiência de 2009 , seria ela reprodutível? Não, é claro, na medida em que nenhuma experiência digna do nome mostra-se, a rigor, verdadeiramente reprodutível. Mas não seria ela, de alguma forma e em alguma medida, emulável, por assim dizer, para fins pedagógicos? Parece-me que sim, e aqui seria preciso enfrentar o desafio imposto por aquele aspecto da referida experiência que se apresenta como o menos razoavelmente passível de emulação futura, a saber: seu declarado caráter de "levantamento e verificação de hipóteses". ${ }^{10}$

Se cada uma das hipóteses sucessivamente levantadas ao longo do curso pôde ser, cada qual a seu tempo, isoladamente confirmada, ao fim, e em conjunto, entretanto, todas elas passaram a se afigurar possivelmente corretas, mas não compossivelmente corretas. Ora, a própria "grande lição" anteriormente enunciada teria mesmo aflorado, em última instância, da percepção desse estado de coisas, e o negar-se a formalizá-la, a referida lição, num teorema qualquer, não significa que se tenha deixado de assimilá-la. Isso, a rigor, impede que se venha a recolocar, doravante, em novas ocasiões, aquelas mesmas antigas hipóteses a título de hipóteses a serem, de fato, efetivamente verificadas - a menos, é claro, que, com fins pedagógicos, assim se procedesse apenas fingidamente. No entanto, poder-se-ia perguntar, "hipótesesfingidamente-levantadas-com-fins-pedagógicos" (ou com quaisquer outros fins) continuariam, de fato e de direito, a ser hipóteses, isto é, conservariam sua natureza e sua função propriamente hipotéticas na ordem do pensamento e da construção do conhecimento, ou já teriam se transformado em alguma outra coisa?

Em vista dessa indagação, faz-se especialmente oportuno o aparecimento da edição brasileira, exatamente um século depois da publicação original, de Die Philosophie des Als Ob [A filosofia do como se] (1911), livro no qual Hans Vaihinger pioneiramente estabeleceu a distinção epistemológico-metodológica entre "Hypothese" [hipótese] e "Fiktion" [ficção]. Ocupando-se, então, do que denomina "a atividade fictícia da função lógica" [die fiktive Tätigkeit der logischen Funktion], "a atividade fictícia no interior do pensamento lógico" [die fiktive Tätigkeit innerbalb der logischen Denkens], atividade esta cujos produtos seriam as "ficções", Vaihinger explica que tais "ficções", enquanto 
"suposições que são externamente semelhantes às hipóteses", foram habitualmente tratadas como hipóteses, mas que, a rigor, ficção e hipótese "são imensamente diferentes [himmelweit verschieden], apesar da semelhança de sua aparência" (VAIHINGER, 1922, p. 124).

Essa diferença fundamental entre ambas se manifestaria, bem entendido, em três níveis básicos. O primeiro, aquele da relação estabelecida por cada uma delas com a realidade então investigada: relação de correspondência à realidade, no caso da hipótese; relação de contradição com a realidade, no caso da ficção. Enquanto a hipótese "dirige-se sempre à realidade [geht stets auf die Wirklichkeit]: isto é, a construção de representações nela contida faz a reivindicação ou tem a esperança de coincidir com uma percepção por se dar" (Ibid., p. 144), na ficção, "é sempre notável um desvio arbitrário da realidade [eine willkürliche Abweichung von der Wirklichkeit], portanto uma contradição com a mesma" (Ibid., p. 172). Assim: "Enquanto toda hipótese quer ser uma expressão adequada da realidade ainda desconhecida e reproduzir acuradamente essa realidade objetiva", conclui Vaihinger (Ibid., p. 606), "a ficção se estabelece com a consciência de que é um modo inadequado, subjetivo, figurativo de representação, cuja coincidência com a realidade é excluída desde o princípio”. Em mais de um ponto, Vahinger enfatiza esse caráter autoconsciente da ficção como fição: "a verdadeira ficção", ele diz, "está sempre acompanhada da consciência do conceito fingido, da suposição fingida que não tem nenhuma validade real" (Ibid., p. 127); "consciência da ficcionalidade [Fiktivität], sem a pretensão à facticidade [Faktižität]" (Ibid., p. 173).

Mas se não à facticidade, a que visaria, afinal, uma ficção? Eis o segundo nível da diferença fundamental entre a ficção e a hipótese, o da finalidade de cada uma delas: "A hipótese tem, afinal, apenas finalidade teórica [theoretischen Zweck], de modo a trazer a contexto o dado, a preencher as lacunas desse contexto [...], bem como a determinar as invariabilidades últimas e, na verdade, primárias", explica Vaihinger (Ibid., p. 148), "ao passo que toda ficção tem estritamente admitida apenas uma finalidade prática [praktischen Zweck] na ciência, posto que não cria um conhecimento propriamente dito" (Ibid., p. 148). Isso significa que, uma vez cumprida tal finalidade prática, a ficção há de ser descartada, em vez de, como sói acontecer com a hipótese, devidamente assimilada: "A diferença real entre ambas, portanto, é a de que a ficção é mera estrutura de apoio [blosses Hilfsgebilde], mero atalho, mero andaime que deve ser novamente desmontado, ao passo que a hipótese espera uma fixação definitiva” (Ibid., p. 148). 
No que tange ao cumprimento ou não dessas respectivas finalidades no âmbito efetivo da construção do conhecimento, avulta o terceiro nível da diferença fundamental entre a ficção e a hipótese, o da forma de legitimação de cada uma delas na práxis científica: "À verificação da hipótese corresponde a justificação da ficção. Aquela deve ser confirmada pela experiência, assim como esta deve ser justificada pelos serviços que presta, afinal, à ciência empírica [Erfahrungswissenschaft]" (Ibid., p. 150). E ainda:

\footnotetext{
Quando uma estrutura fictícia de representação [ein fiktives Vorstellungsgebilde] é estabelecida, então o direito e a escusa para tanto devem ser derivados de que essa estrutura preste serviço ao pensamento discursivo e demonstre-se um recurso útil ao mesmo. [...] Ficções que não se justificam, isto é, que não se deixam justificar como úteis e necessárias devem ser eliminadas do mesmo modo como hipóteses que carecem de verificação (Ibid., p. 150).
}

Claro está, pois, que nossas antigas hipóteses de trabalho, ao serem, então, eventualmente reencenadas, em novas ocasiões pedagógicas, no âmbito de uma investigação acerca da verdadeira natureza e do verdadeiro valor da literatura e, consequentemente, do modo correto de leitura crítica da obra literária, já não poderiam consistir, a rigor, em genuínas hipóteses, mas tão somente em ficções, no sentido vaihingeriano do termo. A sugestão a ser feita pelo professor, num dado momento de uma dada ocasião pedagógica, de que a teoria crítica correta é aquela pautada pela concepção de literatura-como-representação-e-efeito, a verificar-se, e, então, de literatura-como-expressão-de-uma-dimensão-autoral, a verificarse, e, então, de literatura-como-instauração-de-uma-realidade-pela-linguagem, a verificar-se, etc., já não poderá revestir-se, para ele próprio, naquele momento, senão de um caráter de consciente e deliberada contradição com a realidade, já que não acredita haver nenhuma teoria crítica passível de ser aprioristicamente aventada como a teoria crítica correta, todas as teorias afigurando-se como (incom)possivelmente corretas. Tal expediente pedagógico só se veria, pois, devidamente justificado, em vista da finalidade prática a que visaria cumprir, a saber: a de concorrer para a emergência daquele horizonte de indecidibilidade epistemológico-axiológica a partir do qual o ato crítico como dupla decisão se faz a um só tempo necessário e impossível.

Tudo se passará, desse modo, em sala de aula, apenas como se uma determinada teoria crítica estivesse, então, de fato sendo sugerida como a abordagem correta e definitiva do texto literário, isto é, apenas como se estivesse de fato sendo levantada uma hipótese a ser efetivamente verificada, para que, uma vez elaborado o protocolo 
de leitura teoricamente orientado, o procedimento se veja repetido em face de uma outra teoria crítica, francamente oposta à anterior, ensejando-se, com isso, um novo protocolo, etc. Em vista dessa dinâmica pedagógica ficcional, por assim dizer, que deliberadamente apenas simularia um procedimento de levantamento e verificação de hipóteses, e do fato de que a forma linguística por excelência da ficção segundo Vaihinger é mesmo o "als ob", o como se - daí, é claro, o próprio título de seu livro -, poder-se-ia falar, aqui, numa "Pedagogia do Como Se" para os estudos literários. ${ }^{11}$

Em face da iminente cristalização da reflexão pedagógica na imagem de uma determinada Pedagogia, impõe-se ressaltar que terá concorrido para a elaboração dessa imagem o alinhamento do ponto de vista reflexivo aqui em cena com o ponto de vista de apenas um dos polos da relação pedagógica: o docente, e não o discente. Em outras palavras, uma "Pedagogia do Como Se" só se mostra concebível como tal pelo ponto de vista do professor, que é quem deve deter, de partida, a consciência do caráter ficcional do trabalho de "levantamento e verificação de hipóteses" a ter lugar no curso, e não do ponto de vista do aluno, que deve, antes, realmente levantar e verificar hipóteses, encarando o referido trabalho numa perspectiva factual, não ficcional.

Mas permitir que os alunos acreditem no caráter factual de um trabalho que o professor desde o início sabe ser apenas ficcional não equivaleria a enganá-los? Não, definitivamente, quando se leva em conta que esse "saber" que aí se atribui ao professor engajado numa pedagogia literária do como se consiste numa conquista necessariamente a posteriori, tal como, aliás, a própria "grande lição" acerca da crítica literária que o mesmo professor visa, então, fazer eclodir junto a seus alunos. Reduzida fosse aquela lição a um determinado teorema, ela bem que poderia ser logo de partida facilmente comunicada aos alunos, poupando-se, com isso, um inegavelmente extenso, árduo e exigente percurso de trabalho, tanto aos alunos quanto ao professor; mas, assim, de "lição-a-emergir-aolongo-do-percurso" ela viria a converter-se em "tese-a-ser-ilustrada", ou, pior, em "doutrina-a-ser-incutida”, quiçá doutrinariamente, isto é, naturalizada como a verdade dos fatos. A autoconsciência do ficcional, tanto quanto a referida lição, indissociavelmente dela, aliás, só pode emergir como um insight tardio, quiçá como aquela ressignificação a posteriori do recalcado em jogo na "perlaboração" [Durcharbeitung] freudiana, ${ }^{12}$ como sugere, aliás, o próprio Vaihinger, ao observar que, em relação a um grande número de ficções, 
ocorre "que elas primeiramente são formuladas como hipóteses, e que apenas gradualmente desenvolve-se a consciência de sua significância fictícia [ibrer fiktiven Bedeutung]" (Ibid., p. 174).

O caráter inequivocamente construtivista, pois, conferido por uma pedagogia literária do como se ao advento do conhecimento em sala de aula reabriria espaço, bem entendido, na concepção mesma do processo pedagógico - e a exemplo do que deve ocorrer na concepção do processo psicanalítico - , para a possibilidade efetiva não apenas do imprevisto, mas do próprio fracasso.

\section{REFERÊNCIAS}

ABRAMS, M. H. Introduction: Orientation of critical theories. In: The mirror and the lamp: romantic theory and the critical tradition. London/Oxford/New York: Oxford University Press, 1971 [1953]. p. 3-29. [Ed. bras.: ABRAMS, M. H. Introdução: Apresentação das teorias críticas. In: . O espelho e a lampada: teoria romântica e tradição crítica. São Paulo: Editora Unesp, 2010. p. 19-50.]

Types and orientations of critical theories. In: Doing things with texts: Essays in criticism and critical theory. New York/London: W. W. Norton \& Company, 1989. p. 3-30. ARAÚJO, Nabil (Org.). Diante da lei: uma experiência em Teoria da Literatura. Belo Horizonte: FALE/UFMG, 2010. [Também disponível em: < http://www.letras.ufmg.br/ vivavoz/data1/arquivos/diantedalei-site.pdf $>$ ]

BRASIL. Orientações curriculares para o ensino médio: Linguagens, códigos e suas tecnologias. Brasília: Ministério da Educação, 2006.

Parâmetros Curriculares Nacionais: Linguagens, códigos e suas tecnologias. (Ensino Médio). Brasília: Ministério da Educação, 2000.

PCN+ Ensino Médio: Orientações educacionais complementares aos Parâmetros Curriculares Nacionais: Linguagens, códigos e suas tecnologias. Brasília: Ministério da Educação, 2002.

CANDIDO, Antonio. O método crítico de Sílvio Romero. São Paulo: EdUSP, 1988 [1945].

FRYE, Northrop. Anatomy of criticism: four essays. Princeton (NJ): Princeton University Press, 1971 [1957]. [Ed. bras.: FRYE, Northrop. Anatomia da crítica: quatro ensaios. Trad. de Péricles Eugênio da Silva Ramos. São Paulo: Cultrix, 1973.]

KUHN, Thomas S. The structure of scientific revolutions. 3. ed. Chicago/London: The University of Chicago Press, 1996. [Ed. bras.: KUHN, Thomas S. A estrutura das revoluçöes científicas. 9. ed. Tradução de Beatriz V. Boeira e Nelson Boeira. São Paulo: Perspectiva, 2005.]

REBOUL, Olivier. L'endoctrinement. Paris: PUF, 1977. [Ed. bras.: REBOUL, Olivier. A doutrinação. São Paulo: Companhia Editora Nacional, 1980.]

RICHARDS, I. A. Practical criticism: a study of literary judgement. New York: Harcourt, Brace \& World, 1956 [1929]. [Ed. bras.: RICHARDS, I. A. A prática da crítica literária. Trad. de Almiro Pisetta e Lenita Maria R. Esteves. São Paulo: Martins Fontes, 1997.]

VAIHINGER, Hans. Die Philosophie des Als Ob: System der theoretischen, praktischen, und 
religiösen Fiktionen der Menschheit auf Grund eines idealistischen Positivismus. 7 und 8. Aufl. Leipzig: Feliz Meiner, 1922 [1911]. [Ed. bras.: VAIHINGER, Hans. A filosofia do como se: sistema das ficções teóricas, práticas e religiosas da humanidade, na base de um positivismo idealista. Trad. de Johannes Kretschmer. Chapecó (SC): Argos, 2011.]

\section{NOTAS}

${ }^{1}$ Esta e as demais traduções de trechos em língua estrangeira neste artigo são de responsabilidade do autor.

${ }^{2}$ É patente, com efeito, nos PCNEM, a inflexão conceitual da "literatura" para a "cultura", então definida como "toda manifestação que emana das trocas sociais e é transmitida através das gerações", incluindo-se, aí, "a língua, a música, a arte, o artesanato, entre tantas outras" (BRASIL, 2002, p. 63), bem como o imperativo de "aceitação" e "respeito" às manifestações culturais, nacionais e internacionais, em toda sua diversidade: "A observação de que os valores presentes em cada momento histórico são variáveis pode conduzir com mais consistência à aceitação de determinados produtos levando em conta seu contexto. [...] Os bens concernentes às diversas culturas costumam revelar uma dupla faceta: por um lado, expressam valores locais; por outro lado, sintetizam simbolismos universais. Por ambos os motivos devem ser respeitados e preservados" (Ibid., p. 69).

${ }^{3}$ Focando, mais especificamente, o Ensino Médio desses alunos, sua educação literária escolar limitara-se, em linhas gerais, ao tipo de estudo histórico-literário anteriormente referido, no qual, à abordagem prioritária dos estilos de época na literatura brasileira, associase um tratamento difuso dos gêneros literários, bem como, eventualmente, uma divulgação de categorias de análise formal da narrativa e da poesia.

${ }^{4}$ De um modo geral, esta ou aquela das quatro concepções figurou, se não de maneira exclusiva, ao menos de maneira hegemônica em cada um dos questionários respondidos, isso no que diz respeito à questão (a). Com alguma frequência, houve discrepância, no mesmo questionário, entre a concepção manifestada em (a) e a manifestada em (b) ou (c). Essa diversidade interna não foi por mim escamoteada ao comentar as respostas com os alunos; pelo contrário, procurei destacá-la. O que me interessava, naquele primeiro momento, era que pudessem visualizar a diversidade de respostas passíveis de ser aventadas para as mesmas questões.

${ }^{\mathbf{5}}$ Acerca da célebre experiência pedagógica sobre o "julgamento literário" que levara a cabo no início do século passado, e documentada no hoje clássico Practical criticism (1929), I. A. Richards afirmará, com efeito, a certa altura de seu livro, ter encontrado nos exercícios de leitura literária de seus alunos "abundância de exemplos vivos [living instances] de famosas doutrinas críticas que são frequentemente consideradas como sendo agora meramente curiosidades de opinião há muito extintas [merely curiosities of opinion long since extinct]" (RICHARDS, 1956, p. 7).

6 “Diante da lei está um porteiro. Um homem do campo chega a esse porteiro e pede para entrar na lei. Mas o porteiro diz que agora não pode permitir-lhe a entrada. O homem do campo reflete e depois pergunta se não pode entrar mais tarde. - É possível - diz o porteiro.- Mas agora não. Uma vez que a porta da lei continua como sempre aberta e o porteiro se põe de lado o homem se inclina para olhar o interior através da porta. Quando nota isso o porteiro ri e diz: - Se o atrai tanto tente entrar apesar da minha proibição. Mas 
veja bem: eu sou poderoso. E sou apenas o último dos porteiros. De sala pra sala porém existem porteiros cada um mais poderoso que o outro. Nem mesmo eu posso suportar a simples visão do terceiro. O homem do campo não esperava tais dificuldades: a lei deve ser acessível a todos e a qualquer hora, pensa ele; agora, no entanto, ao examinar mais de perto o porteiro, com seu casaco de pele, o grande nariz pontudo, a longa barba tártara, rala e preta, ele decide que é melhor aguardar até receber a permissão de entrada. O porteiro lhe dá um banquinho e deixa-o sentar-se ao lado da porta. Ali fica sentado dias e anos. Ele faz muitas tentativas para ser admitido e cansa o porteiro com os seus pedidos. Às vezes o porteiro submete o homem a pequenos interrogatórios, pergunta-lhe a respeito de sua terra natal e de muitas outras coisas, mas são perguntas indiferentes, como as que os grandes senhores fazem, e para concluir repete-lhe sempre que ainda não pode deixá-lo entrar. O homem, que havia se equipado com muitas coisas para uma viagem, emprega tudo, por mais valioso que seja, para subornar o porteiro. Com efeito, esse aceita tudo, mas sempre dizendo: - Eu só aceito para você não julgar que deixou de fazer alguma coisa. Durante todos esses anos o homem observa o porteiro quase sem interrupção. Esquece os outros porteiros e este primeiro parece-lhe o único obstáculo para a entrada na lei. Nos primeiros anos amaldiçoa em voz alta e desconsiderada o acaso infeliz; mais tarde, quando envelhece, apenas resmunga consigo mesmo. Torna-se infantil e uma vez que, por estudar o porteiro anos a fio, ficou conhecendo até as pulgas da sua gola de pele, pede a estas que o ajudem a fazê-lo mudar de idéia. Finalmente sua vista enfraquece e ele não sabe se de fato está ficando mais escuro em torno ou se apenas seus olhos o enganam. Não obstante reconhece agora no escuro o brilho que irrompe inextinguível da porta da lei. Mas já não tem muito mais tempo de vida. Antes de morrer, todas as experiências daquele tempo convergem na cabeça para uma pergunta que até então não havia feito para o porteiro. Faz-lhe um aceno para que se aproxime, pois não pode mais endireitar o corpo enrijecido. O porteiro precisa curvar-se profundamente até ele, já que a diferença de altura mudou muito em detrimento do homem: - O que é que você ainda quer saber? - perguntou o porteiro - Você é insaciável. - Todos aspiram à lei - diz o homem. - Como se explica que em tantos anos ninguém além de mim pediu pra entrar? $\mathrm{O}$ porteiro percebe que o homem já está no fim e para ainda alcançar sua audição em declínio ele berra: - Aqui ninguém mais podia ser admitido, pois esta entrada estava destinada só a você. Agora eu vou embora e fecho-a." KAFKA, Franz. Diante da lei. In: Um médico rural: pequenas narrativas. Tradução de Modesto Carone. São Paulo: Companhia das Letras, 1999. p. 27-29.

${ }^{7}$ A escolha de Kafka para esse propósito justificava-se, em vista do curso como um todo, por ser ele um autor cuja fortuna crítica: (a) é variada o suficiente para contemplar as diversas perspectivas críticas a serem trabalhadas ao longo do semestre e (b) está disponível, nessa sua variedade, em língua portuguesa.

${ }^{8}$ Apoio-me, quanto a isso, em Olivier Reboul, que, em seu pequeno tratado, hoje clássico, sobre L'endoctrinement [A doutrinação] (1977), afirma: “Não existe doutrina certa, evidente, e entretanto não se pode privar-se de doutrina para viver. A doutrinação começa quando a doutrina, em lugar de ser um auxílio para aqueles a quem se ensina, que lhes permita sentir melhor, compreender melhor, viver melhor, torna-se um fim que os subjuga. É nesse caso que se a ensina [a doutrina] de forma unilateral, conferindo-lhe uma modalidade que não é a sua, tratando como ciência o que não passa de crença”" (REBOUL, 1977, p. 192-193).

${ }^{9}$ Para uma visão de conjunto dos textos teóricos, críticos e literários consultados pelos alunos na elaboração de todos os protocolos ao longo do curso, cf. ARAÚJO (2010, p. 101-102). 
${ }^{10}$ Penso aqui na "emulação futura" da referida experiência não apenas em nível universitário, em nossos cursos de Letras, mas também, é claro, em nosso Ensino Médio, na medida em que os graduandos em Letras de hoje estão sendo preparados para lecionar língua e literatura na educação básica do país.

${ }^{11}$ O filósofo e pedagogo italiano Giovanni Marchesini (1868-1931) - cujo livro Le finzioni dell'anima [As ficções da alma], de 1905, Vaihinger (1922, p. xvi) menciona bastante elogiosamente - é autor, também, de La finzione dell'educazione o la pedagogia del Come se [A ficção da educação ou a pedagogia do Como se] (1925), título de clara inspiração vaihingeriana. Como não me foi possível consultar a obra em questão, o que proponho, então, sob a rubrica "Pedagogia do Como Se" tem única e exclusivamente como referência o livro do próprio Vaihinger.

${ }^{12}$ Cf. o verbete "Perlaboração", in: LAPLANCHE, J.; PONTALIS, J.-B. Vocabulário da psicanálise. 7. ed. Trad. de Pedro Tamen. São Paulo: Martins Fontes, 1983. p. 429-431.

Recebido: 01/08/2013

Aprovado: 29/09/2014

Contato:

Universidade Federal de Minas Gerais

Faculdade de Letras

Av. Antônio Carlos 6627, Pampulha

Belo Horizonte $|\mathrm{MG}|$ Brasil

CEP 31.270-901 